\title{
Book Review: A Guide to Academic Writing and Research Reports by Senior Prof. Dr. Mangala Fonseka and Dr. Athula Manawaduge
}

\section{N.J. Dewasiri}

University of Sri Jayewardenepura

\section{N. Abeysekera}

The Open University of Sri Lanka

\section{G.D. Samarasinghe}

University of Moratuwa

Scholarly or academic writing is clear, concise, planned, coherent, and backed up by evidence. Its purpose is to aid the reader's understanding. Hence, it consists of a formal style and tone. Further, it does not require the use of long sentences and instead uses clear and concise language with simple vocabulary. Research report writing is an integral part of academic writing. Hence, both academic and research report writing play a vital role in developing a multitude of researchers across the globe. The authors of the book entitled "A Guide to Academic Writing and Research Reports" identified such a role to develop prolific researchers amongst the student community both within and outside the university in Sri Lanka.

The book is organized into two parts. The first part is devoted to the basics of academic writing which contains seven chapters. The second part is dedicated to writing research reports and consists of six chapters. There are books written separately focusing on research report writing and academic writing. For instance, Uyangoda (2010) focused on research proposal writing whereas Nanayakkara (2008) emphasized academic and professional writing in

\section{Corresponding Author:}

Dewasiri, N.J., Visiting Lecturer, University of Sri Jayewardenepura, E-mail: jayantha@postgraduate.edu.lk 
Management. There is a paucity of books written incorporating these two essential elements in a single piece of work; Academic Writing and Research Reports. Addressing this gap, the authors intended to produce this distinctive handbook titled "A Guide to Academic Writing and Research Reports" that especially addresses the academic writing needs of university students in the management discipline in Sri Lanka.

The purpose of the first chapter is to provide an overview of academic writing. The nature and role of academic writing are discussed in the first phase. Then, the STF model is proposed as a process of academic writing emphasizing the theme. The authors argued that "A well-developed essay consists of an attractive start (S), a well-organized text/body (T) that is complete with facts, and a fined-tuned finish (F), summary". Then, a brief description is further provided on the STF model. Further, this chapter is focused on the basic features of academic writing. Accordingly, focus, impartiality, tone, and governing rules, norms, and procedures were identified as key features of academic writing. Moreover, the authors have emphasized the importance of preparatory work as the last section of the first chapter.

The second chapter focuses on a guide to writing good paragraphs. First, the role of the paragraph is discussed. The authors argue that a 'well-developed and appropriately arranged' paragraph paves the way towards a synergistic effect on the overall academic work. Then, the components of a paragraph are discussed in terms of the three-component model; topic sentence, supporting sentences and concluding in light of the STF model. Then, paragraph writing is exemplified using two well-developed examples based on the STF and threecomponent models. Finally, the deviations from well-developed paragraphs are discussed in terms of long paragraphs and the introduction of the connecting sentences using suitable examples. The reviewers believe that the authors win the heart of the audience through the exemplification of writing good paragraphs.

The third chapter focuses on the writing of academic essays. The authors provide a step-wise guide on writing an academic essay with suitable examples. First, the selection of a theme is discussed as an arduous process. The authors argue that the selection of a theme should be based on an area of interest in order to win the readers' minds. Then, the development of the essay structure is comprehensively discussed using the STF model and suitable examples. The authors argue that the emergence of the theme should be at the beginning of the 
essay through the deductive reasoning approach instead of a consequence of synthesis and discussion. They further assert that the introduction should cover the background, objectives, scope, significance, methods, and organization of the essay. Then, the text or body could be drafted with well-developed paragraphs as stated in chapter two. The authors highlight the importance of the conclusion section as the concluding remarks of an essay. Here, it is required to conclude on a high note with an assertion of the theme, and recommendations, limitations, and future directions in a concise manner. Finally, the difference between the research reports and academic essays is comprehensively discussed. The authors emphasize that a research report can be considered as an advanced version of the academic essay since both are built on a common platform; the STF model.

Chapter 4 is devoted to the determinants of writing style. The writing style is identified as the major determinant of the tone of academic work. The authors emphasize that the purpose of writing style is to bring simplicity and clarity while convincing readers to stay engaged and interested. Here, the major determinants such as type of academic work, editorial requirements, unity, congruence and balance, narration, economy, length of sentences/paragraphs, jargon, smoothness of expression, clarity, and precision have been comprehensively discussed. Finally, the authors argued that a systematic approach to developing one's writing style requires extensive hard work and perseverance. The next chapter focuses on the use of language in academic writing. It provides guidance on the proper use of language in scholarly work. First, the importance of grammar is briefly discussed as a part of the speech and construction of sentences. Then, the use of prepositions, conjunctions, and determiners are briefly presented. Next, the use of punctuation marks is discussed in terms of a full stop, question marks, exclamation mark, commas, semi-colons, colons, dashes, hyphens, apostrophe, and inverted commas. Then, the importance of spelling and capitalization is discussed in nutshell. Finally, the noticeable differences between British vs. American English are discussed along with Ceylonisms which are to be eliminated by the Sri Lankan academic writers. It is imperative to note that the authors do not cover every aspect of grammar in this chapter given that this is not a grammar book.

The aim of the sixth chapter is to provide guidance in terms of writing tutorials, examination questions, short papers such as theoretical and empirical papers, and case narrations. Here, the use of common lead terms in tutorials and 
examinations are demonstrated using the handbook 1 of the taxonomy of educational objectives (Bloom et al., 1956). Further, the structures for a theoretical paper, empirical paper, and case narration are tabulated with a short discussion. Finally, the ways and means of enhancing the vocabulary are discussed in terms of the use of formal words and in-text referencing. Here, the words used in in-text referencing are tabulated based on the Harvard Referencing Style. The last chapter of basic academic writing focuses on the psychological and behavioral aspects related to academic writing. First, the role of a calm mindset in terms of creativity and free-thinking is explained. Then, a guideline for scientific writing is presented as a seven-step process. Then, the importance of ethical behavior and plagiarism is discussed in a comprehensive manner. The use of software packages such as 'Turnitin' is briefly described in order to maintain the author's originality in academic writing. Moreover, the concurrent use of listening, reading, and speaking is emphasized as strategies in developing scientific writing skills. Further, the role of typologies such as content vs. form is discussed to achieve a flagship status which is rich in content and strong form. Finally, the ways and means of improving academic writing are discussed as a journey with good practices.

The potter's creation has left the poet speechless and parched. One hopes of course that the beautifully crafted pieces of academic writing will not produce the same effect. But the potter's craft certainly makes the poet happy, happy, and that is the effect that should be the product of a good piece of academic writing as emphasize by the authors throughout the first part of the book.

The second part of the book begins with chapter 8 and it focuses on writing research proposals and reports. Chapter 8 provides an overview of management research. Here, two basic approaches to management research have been identified as quantitative vs. qualitative research. As Bryman (2012) noted, the quantitative and qualitative approaches have been further distinguished based on the role of theory in relation to the research, ontological orientations, and epistemological orientations. The role of theory is described as quantitative research in relation to the deductive approach whereas the qualitative research lies in relation to the inductive approach. The ontological and epistemological orientations of quantitative and qualitative approaches are further discussed in this chapter. Then, the quantitative research process and qualitative research process are further exemplified briefly describing the rationale for such an approach. Next, the role and uses of the mixed methods approach are discussed as an alternative approach to management research. Finally, the selection of a 
suitable theme for a study is briefly discussed in this chapter as a concluding remark. The reviewers believe that methodological rigor could be further improved in this section if the authors could have an in-depth discussion with a more pragmatic tone on the rationale for selection of each approach (qualitative, quantitative, and mixed methods) based on the type and the nature of the research questions/problems as explained by Onwuegbuzie and Leech (2006) and Dewasiri et al. (2018).

Chapter 9 is devoted to an essential part of academic writing; referencing. The authors emphasized on available referencing systems such as Harvard, APA, and Chicago referencing styles. The use of the Harvard Referencing style as adopted by the Academic Learning Centre (ALC) of Central Queensland University is exemplified in this book. Here, a comprehensive guide is provided covering essential parts of referencing such as in-text citations and preparation of a reference list. The uses of in-text citations are discussed based on two approaches; the author prominent and information prominent. Then, a guideline in preparing a reference list is further discussed using relevant examples for hard copy books, e-books, hardcopy journal articles, e-journal articles, newspaper articles, reports, conference proceedings, audio-visual media, and other documents in the World Wide Web (WWW). Finally, the differences between bibliography and references are briefly discussed in this chapter.

Chapter 10 focuses on writing research proposals. First, the components of a quantitative research proposal are discussed in relation to the positivistic paradigm. Here, the title, abstract, the components of the introduction chapter such as background, research problem, research questions, and objectives, definitions of the key-terms, significance, scope, and limitations are further discussed. Then, the components of the literature review are briefly presented. Next, research design, methods, summary and conclusions, and plan of the study along with the references and appendices are briefly discussed in relation to the quantitative approach. Second, the components of qualitative research (interpretivistic) proposal are also discussed in terms of the title, abstract, components of the introduction, literature review, empirical site, theoretical/analytical framework, methods, summary and conclusions, plan of the study, references, and appendices. It is important to note that the authors were highly focused on explaining quantitative proposals than qualitative proposals in this chapter. The reason is that most of the researchers in accounting discipline are highly focused on the quantitative paradigm, hence the 
reviewers believe that the authors tend to weight on the same even if there is an accounting stream on critical perspective is on rise in the West.

The next chapter focuses on the components of a research report in terms of quantitative and qualitative approaches. Accordingly, the components of a quantitative research report are exemplified in terms of preliminary pages, abstract, introduction chapter, literature review, research design and methods, data analysis and findings, discussion, conclusions and recommendations, references, and appendices. Then, the components of a qualitative bounded research report are discussed in the same manner. Finally, the components of abstract, chapter introduction and summaries, use of footnotes, endnotes, and appendices are discussed exemplifying the components of preliminary pages of a research report.

Chapter 12 discusses formatting requirements of research reports in terms of paper to be used, font size, margins, page numbers, appendices, line spacing, headings, subheadings, tables, and figures using suitable examples. This chapter provides clear guidance on the formatting requirement of a research report especially for the students of the Department of Accounting, University of Sri Jayewardenepura. The reviewers believe that the guidelines provided by the authors could be vastly used by researchers irrespective of their specializations.

Finally, the authors discuss the research administration procedures of the Department of Accounting at the University of Sri Jayewardenepura as the last chapter of the book. First, the mandatory requirement of the research component is briefly described as per the Sri Lanka Qualifications Framework (SLQF). Then, the research process of the Department of Accounting is presented. Next, the steps of the research proposal and report development and evaluation processes are comprehensively discussed. The volume of the research report and dissertation along with the publication opportunities are discussed as a further step.

The book is masterfully written so that students can clearly understand the ways and means of writing research reports using academic/scientific writing techniques. The authors effectively communicate the main points by using realworld examples, anecdotes, and cases that captivate interest and attention. For anyone interested in understanding how to write a research proposal or report using academic writing methods, A Guide to Academic Writing and Research Reports is an ideal textbook. Last but not least, the reviewers would like to 
BOOK REVIEW: A GUIDE TO ACADEMIC WRITING AND RESEARCH REPORTS BY SENIOR PROF. DR.

comment on the cover page of the book. The potter's creation is not for admiration and praise but for use by society. The metaphor of the potter and his craft as the cover page story of this book on academic and research report writing is indeed cogent for this timely and much needed book.

\section{References}

Bloom, B. S., Engelhart, M.D., Furst, E.J., Hill, W.H., Krathwohl, D.R. (1956). Taxonomy of Educational Objectives. Vol. 1: The Cognitive Domain. McKay: New York.

Bryman, A. (2012). Social research Methods, $4^{\text {th }}$ edi, Oxford University Press: Oxford.

Dewasiri, N.J., Weerakoon Banda, Y.K. and Azeez, A.A. (2018) Mixed Methods in Finance Research: The Rationale and Research Designs, International Journal of Qualitative Methods, 17, pp. 1-13.

Nanayakkara, G. (2008). A handbook for academic and professional writing in management, Postgraduate Institute of Management: Colombo

Onwuegbuzie, A. J., \& Leech, N. L. (2006) Linking research questions to mixed methods data analysis procedures. The Qualitative Report, 11, 474-498.

Uyangoda, J. (2010). Writing Research Proposals in the Social Science and Humanities:

A Theoretical and Practical Guide, Social Scientists, Association (SSA): Colombo. 